\title{
Poverty and Employment Status as Determinants of Willingness to Pay for the Improvement of Environmental Quality in Low-Income Neighbourhood: The Case of Bophelong Township (South Africa)
}

\author{
Ismael Maloma \\ School of Economic Sciences, \\ North-West University, Vanderbijlpark, South Africa \\ E-mail: ismael.maloma@nwu.ac.za \\ Mmapula Brendah Sekatane \\ School of Economic Sciences, \\ North-West University, Vanderbijpark, South Africa \\ North-West University, Vanderbijpark, South Africa
E-mail: brendah.sekatane@nwu.ac.za
}

Doi:10.5901/mjss.2014.v5n1p691

\begin{abstract}
The introduction of any substance into the environment that leads to the deterioration in the ambient quality of the environment is deemed as pollution (including air-pollution). Based on this environment legislation is often promulgated to minimise the negative impact of human actions on the environment. This study investigates the determinants of willingness to pay for the improvement in environmental quality in a South African Township of Bophelong. The OLS regression was used to investigate the effect that poverty and employment status has on the willingness to pay for a smoke free environment. The results of the study indicate that both employment and poverty status are significant determinants of the willingness to pay for a smoke free environment but poverty status has a negative coefficient whereas employment status has a positive coefficient. On average people who are employed are willing to pay more for a smoke free environment than those that are unemployed.
\end{abstract}

Keywords: Poverty, Unemployment, Environment, Willingness to pay, Poor

\section{Introduction}

Reducing unemployment and alleviating poverty are key policy goals in many developing countries, yet progress remains elusive on both fronts (Agénor, 2005:115). According to Saunders (2002:25), unemployment is a bad thing. It is bad for the economy and for society, for unemployed people themselves, for their families and for the communities in which they live. High and persistent unemployment presents a major challenge for the welfare state from two directions: firstly, it erodes the funding base and secondly, it increases the demands on welfare programs because of the consequences for poverty and inequality resulting from high unemployment. Field (2010) note that it is a common understanding that a high unemployment rate means that more people are out of work and therefore more people have fallen into poverty. But the relationship between unemployment and poverty is complex, and the two may not always relate very directly.

Poverty is often discussed in different platforms as a static concept, where a group of people are labelled permanently 'poor' and the rest are not. In fact, poverty is highly dynamic, reflecting the shifting nature of both individual income and family change. Research on the dynamics of poverty typically breaks down the experience into different types. For example, it can be described as 'persistent' (long periods of poverty), 'recurrent' (cycling in and out of poverty) and 'transient' (in poverty only briefly) (Goulden, 2010:3). Poverty is considered to contribute to pollution as the poor are more likely to pollute than the affluent members of society (Beall et al., 2000:833). The higher the per capita income of a particular community the lower is the ambient concentration of water and air-pollution (Hilton, 2006:130). Laderchi et al. (2003:244) describe four different approaches to the definition of poverty. Firstly, the monetary approach describes poverty in the context of a shortfall in income related to a pre-determined figure referred to as the poverty line. Any individual whose income fall below this predetermined figure is regarded as being poor. Secondly, the capability approach defines poverty as a lack of ability to attain a certain minimum of basic capabilities such as nutrition. Thirdly, 
the social exclusion approach views poverty as a state of affairs where an individual or groups are totally or partially excluded from full participation in the community in which they stay. Lastly, the participatory approach promotes the involvement of the poor in defining poverty (Laderchi et al., 2003:244).

The study analyse poverty and employment status as determinants of willingness to pay for the improvement of environmental quality in Bophelong Township. The aim of the study is to understand the relationship between poverty and employment status and therefore analyse the two variables as determinants of willingness to pay for a smoke free environment. Section 2 of the paper reviews the literature of the study. Section 3 presents the methodology used in the data collection process and the data analysis. The OLS regression used to investigate on the determinants of willingness to pay for the smoke free environment is also specified in this section. Section 4 presents the results and discussion, and section 5 is the conclusion.

\section{Literature review}

Pollution is defined as the introduction into the environment of substances or energy liable to cause hazards to human health, harm to living resources, and ecological systems, damage to structure or amenity, or interference with legitimate use of the environment (Kidd, 1997:121). In addition, the National Environmental Management Act 39 of 2004 defines air-pollution as any change in the composition of air caused by smoke, soot, dust (including fly ash), cinders, solid particles of any kind, gases, fumes, aerosols and odorous substances. Human beings exist in an environmental space. The environment offers a great deal of services to mankind; firstly, the environment acts as a form of a consumption good by offering services to humankind in the form of air to breath and space; secondly, the environment supply resources such as water, sun and oil; thirdly, the environment is a recipient for waste through the atmosphere, land and water and lastly, the environment acts as a geographical location for economic activities.

According to the WHO (2002) there is a negative relationship between economic growth and pollution. The negative correlation between economic growth and pollution is further confirmed by various researches conducted by the World Health Organisation (WHO, 2002), which indicates that more than three billion -mostly poor - people in the world who do not possess sufficient resources to afford cleaner forms of energy still use wood, dung, coal and other solid fuels for cooking. More than one and half million people die annually as a result of pollution originating from the use of biomass and fossil fuels. Poverty is considered to contribute to pollution as the poor are more likely to pollute than the affluent members of society (Beall et al., 2000:833). The higher the per capita income of a particular nation the lower is the ambient concentration of water and air-pollution (Hilton, 2006:130).

One of the major factors that contribute to pollution in Bophelong is the continued combustion of bio-fuels, particularly coal. Despite the fact that almost $100 \%$ of the households have electricity in their houses, many residents still continue to use coal due to its affordability and multiple uses. Electricity on the other hand is considered more expensive and the situation is likely to continue for a long time in the future. Approximately $3 \%$ of coal used in the country is consumed by households and this combustion is responsible for approximately $20 \%$ of national particulate emissions (Wagner et al., 2005:2).

\section{Methodology}

\subsection{Survey Design}

The survey on which this study was based formed part of a broader socio-economic survey undertaken in a low-income neighbourhood of Bophelong Township (South Africa) in 2013. The survey included an environmental section which made use of contingent valuation questions to elicit households' maximum willingness to pay for the improvement in the quality of their environment. As the environmental section of the questionnaire formed part of a broader study, this paper is restricted in as far as the choice of an elicitation format is concerned and had to use the elicitation format that was used in the survey namely, an open-ended elicitation format. The open-ended elicitation format involves asking respondents the maximum amount that they are willing to pay for an environmental good or policy. Open-ended questions are deemed desirable as they generally manage to overcome the problem of starting point bias and secondly, they tend to provide a more conservative result as they tend to produce lower WTP than referendum type questions (Carlsson \& Johansson-Stenman, 2000:662-663). 
A random sample of households were interviewed in the township of Bophelong. Maps were obtained for the area and a sample stratification was designed on account of the geographical distribution and concentration of people in the area. A questionnaire was designed for obtaining the desired information. The area was divided into different extensions and the questionnaires were apportioned evenly among the inhabited sites. Sites at which field workers were supposed to complete questionnaires were identified individually from the map before the field workers went out. However, where people could not be obtained for an interview, or where it was impossible to trace the house, a next pre-selected household was interviewed. Information was obtained from the breadwinner or the spouse. Information obtained from the respondents was kept in strict confidence and the participants were not required to write their names on the questionnaire. A total of 300 households were interviewed by two fieldworkers in July 2013, only 295 were used in the analysis.

\subsection{Measurement of Poverty}

In order to achieve the objective of determining the relationship between the poor and their willingness to pay for environmental quality, a measure of poverty was needed. Following the guidelines of the World Bank (2001), a poor household was defined as a household whose combined income of all its members was less than the cost of minimum calorie intake and that of other necessities of the household. Using the information on household size and household total income, the household poverty status was calculated. Following the poverty measure for South Africa for the year 2009 of R416 (STATS SA, 2008/9), and adjusted it for inflation for the year 2013, a per capita poverty line of R520 was determined. The share of the poor and non-poor in the sample was determined at $51 \%$ and $49 \%$ respectively, half to each category. About $61 \%$ of the heads of households' were found to be unemployed and only $39 \%$ were employed.

\subsection{Regression Model}

In order to find out which variables form the determinants of willingness to pay for a smoke free environment in Bophelong Township, the Ordinary Least Squares regression was used. The OLS was chosen due to the nature of the depended variable, the willingness to pay (WTP) being a continuous variable. The OLS model used in this study is as follows:

$\mathrm{WTP}=\beta_{1}+\beta_{2} X_{2}+\beta_{3} X_{3}+\varepsilon$

Where, WTP is the willingness to pay. It is measured as a stated value, whereby households were asked to state the amount they are willing to pay for a smoke free environment. $X_{2}$ is the poverty status and $X_{3}$ the employment status which are used as determinants for the willingness to pay for a smoke free environment. Poverty status and employment status are dummy variables and defined as 1 for a poor household, 0 for non-poor household and 1 for employment and 0 for not employed.

\section{Results and discussion}

This section of the study presents the results of the respondents' perception about the environment and looks at the relationship between employment and poverty status. The results of the OLS regression are also presented and discussed.

\subsection{Perception about the environment}

About $63 \%$ of the respondents felt that the township is littered, untidy and dirty. Only $32.2 \%$ of the respondents felt that the township is clean and pleasant. About $4.4 \%$ were indifferent about their feeling for the environment. $30.1 \%$ of the respondents stated that they are affected by the pollution in the township and $17.8 \%$ indicated that they are slightly affected. About $27.6 \%$ stated that they are not affected by pollution in the area whereas $6.6 \%$ of the respondents indicated that the pollution in the area is unbearable. 


\subsection{The relationship between employment status and poverty status}

The first objective of the study was to investigate on the relationship between employment status and poverty status among the households in Bophelong. Since both of these two variables are categorical, a chosen analysis was correlation using cross tabulation in SPSS to determine the percentages of those in employment and poor and the percentage of those not employment and poor or not poor.

Table 1 presents the results of the tabulation. The table shows that in the sample, $51 \%$ of the households are poor and $49 \%$ are not poor using the poverty line discussed in sub-section 3.2. It also shows that $61 \%$ are not employed while $39 \%$ of the head of households are employed. Of the unemployed heads of households, $61 \%$ are poor and $39 \%$ are not poor. The $61 \%$ poverty rate within the unemployed category shows that employment has a significant influence on whether one end up above or below the poverty line.

Within the category of the employed, $65 \%$ are not poor and 35\% are poor, almost giving a mirror image of the unemployed category. This association which is significant at $1 \%$ significance level imply that those with a job are more likely to be above the poverty line than those without a job. Other studies that found a similar association between poverty and employment are Islam (2004), ILO (2008) and Hull, (2009). Also the fact that 35\% of those with a job are found below the poverty line indicates the differences in job quality. As pointed out already, this calls for a further analysis in the sectors which these people are working in. A prior expectation will be that the poor $35 \%$ that are employed are mostly in the low skill and low paying jobs. Hence just being employed is not enough to alleviate poverty but the kind of jobs concerned matter as well (Hull, 2009).

Table 1: Relationship between employment status and poverty

\begin{tabular}{|c|c|c|c|c|c|}
\hline & & & ES_Head & & Total \\
\hline & & & unemployed & employed & \\
\hline & & Count & 70 & 75 & 145 \\
\hline & & $\%$ within poverty status & $48.3 \%$ & $51.7 \%$ & $100.0 \%$ \\
\hline & nom poor & $\%$ within ES Head & $38.9 \%$ & $65.2 \%$ & $49.2 \%$ \\
\hline & & $\%$ of Total & $23.7 \%$ & $25.4 \%$ & $49.2 \%$ \\
\hline roverty Stalus & & Count & 110 & 40 & 150 \\
\hline & & $\%$ within poverty status & $73.3 \%$ & $26.7 \%$ & $100.0 \%$ \\
\hline & poor & $\%$ within ES Head & $61.1 \%$ & $34.8 \%$ & $50.8 \%$ \\
\hline & & $\%$ of Total & $37.3 \%$ & $13.6 \%$ & $50.8 \%$ \\
\hline & & Count & 180 & 115 & 295 \\
\hline Total & & $\%$ within poverty status & $61.0 \%$ & $39.0 \%$ & $100.0 \%$ \\
\hline Total & & $\%$ within ES Head & $100.0 \%$ & $100.0 \%$ & $100.0 \%$ \\
\hline & & $\%$ of Total & $61.0 \%$ & $39.0 \%$ & $100.0 \%$ \\
\hline
\end{tabular}

\subsection{Results of the OLS Regression}

On the willingness to pay for a smoke free environment, the regression results have the two hypothesised variables significant. According to Table 2 below, poverty status is significant at 10\% significance level. The coefficient of -354.529 for poverty status is negative which reduces the amount that households are willing to pay for a smoke free environment. Employment status is significant at $5 \%$ significance level with a positive coefficient of 462.894 . This means that employment increases the value that people are willing to pay for a smoke free environment.

The coefficient on poverty status shows that poor people are willing to pay R354 less than the non-poor. On average poor people who are not employed are willing to pay only R99 (453-354) for a smoke free environment. The poor but employed population is willing to pay on average R561 for a smoke free environment. On average, the non-poor but employed population is willing to pay about R915 for the environment. The non-poor and unemployed population is willing to pay only R453. These indicate that employment makes people to be willing to pay more for the quality of the environment. 
Table 2: Results of the OLS Regression

\begin{tabular}{|cl|l|l|l|l|l|}
\hline \multirow{2}{*}{ Model } & \multicolumn{2}{|l|}{ Unstandardised Coefficients } & $\begin{array}{l}\text { Standardised } \\
\text { Coefficients }\end{array}$ & S Sig. \\
\cline { 3 - 5 } & & B & Std. Error & Beta & & \\
\hline \multirow{3}{*}{1} & (Constant) & 453.771 & 174.534 & & 2.600 & .010 \\
& Poverty status & -354.529 & 192.989 & -.130 & -1.837 & .068 \\
& ES_- & 462.894 & 196.751 & .166 & 2.353 & .020 \\
& Head & & & & & \\
\hline
\end{tabular}

For selecting a good model, a number of tools for model adequacy can be employed. According to the analysis of variance the $p$-value was significant at $1 \%$ significance level indicating that the OLS model was a good fit.

\section{Conclusion}

The study was set to investigate on the determinants of willingness to pay for the improvement in environmental quality. The results indicate that poverty is significant but with a negative coefficient meaning that poverty makes people to reduce the value they are willing to pay for the improvement of the environmental quality. Employment was also significant but with a positive coefficient, indicating that when people are employed they are willing to pay more for the improvement of the environmental quality. On average employed people whether poor or non-poor, they are willing to pay more than those that are unemployed. This means that to deal with pollution, authorities' needs to also focus on employment creation policies that will move people out of the poverty trap and encouraging them to be willing to pay more for environmental improvement.

\section{References}

Agénor, P-R. (2005). Unemployment-Poverty tradeoffs. Manchester: University of Manchester and Centre for Growth and Business Cycle Research

Beall, J., Crankshaw, O. \& Parnell, S. (2000). Victims, villains and fixers: The urban environment and Johannesburg's poor. Journal of southern African studies, 26(4):833-855.

Carlsson, F. \& Johansson-Stenman, O. (2000).Willingness to pay for improved air quality in Sweden. Applied Economics, 32(6): 661669

Field, O. (2010). Unemployment and Poverty in Western New York. New York: Partnership for the Public Good

Goulden, C. (2010). Cycles of poverty, unemployment and low pay. United Kingdom: Joseph Rowntree Foundation

Hilton, F. (2006). Poverty and pollution abatement: Evidence from lead phase-out. Ecological economics, 56(1):125-131.

Hull, K. (2009). "Understanding the Relationship between Economic Growth, Employment and Poverty Reduction", (in: OECD-Ed., Promoting pro-poor growth: Employment," OECD, pp. 69-94

ILO (International Labour Organisation). (2008). "Promotion of rural employment for poverty reduction" International Labour Conference 97th Session, Geneva: International Labour Office.

Islam, R. (2004). The Nexus of Economic Growth, Employment and poverty reduction: an empirical analysis. Geneva: Recovery and Reconstruction Department International Labour Office.

Kidd, M. (1997). Environmental law.Cape Town: Juta.

Laderchi, C.R., Saith R. \& Steward, F. (2003). "Does it matter that we do not agree on the definition of poverty? A comparison of four approaches" Oxford development studies. 31 (3), 243-274.

Saunders, P. (2002). The direct and indirect effects of unemployment on poverty and inequality. Sydney: The Social Policy Research Centre University of New South Wales

STATS SA (Statistics South Asfrica). (2008/9). Poverty Profile of South Africa: Application of the poverty lines on LCS 2008/2009, Pretoria: Statistics South Africa

Wagner, N., Schoonraad, P., Swanepoel, P., Van Niekerk, A., Scholtz, C. \& Kornelius, G. (2005).Results of domestic smoke reduction programmes at eMbalenhle (Mpumalanga) and Zamdela (Free State). http://www.airshed.co.za/archive/Domestic\%20smoke\%20reduction\%20NACA\%202005.pdf [Accessed 23 September 2011].

WHO (World Health Organisation). (2002). Addressing the links between indoor air pollution, household energy and human health. Geneva: WHO 
E-ISSN 2039-2117

ISSN 2039-9340
Mediterranean Journal of Social Sciences MCSER Publishing, Rome-Italy
Vol 5 No 1 January 2014

World Bank. (2001). Poverty Manual. Washington D.C: The World Bank Group. 